\section{DEPRESSION AFTER HIP FRACTURE}

Two reports in this edition of the Journal of the American Geriatrics Society (JAGS) address the incidence, prevention, and treatment of depression after hip fracture, which has been reported over the wide range of $9 \%$ to $47 \% .^{1}$ Although prevalence rates of depression in older adults with hip fractures seem similar to rates in other comorbid medical disorders, ${ }^{2}$ it is clear that these two prominent medical conditions - depression and hip fracture - account for a significant amount of morbidity and mortality in the elderly population and that depression in this context carries a significant risk of poorer outcomes or mortality. ${ }^{3-5}$ Even without depression, only $20 \%$ of hip fracture patients return to their preoperative functional level after hip repair. ${ }^{6}$ Recent data from the National Health and Nutrition Examination Survey suggest that depression is associated with a greater risk of hip fracture, with a hazard ratio of $1.9 .^{7}$ Depression has also been associated with a greater risk of falls; $30 \%$ to $60 \%$ of community-dwelling older patients and $43 \%$ of institutionalized older persons fall each year. ${ }^{8}$ In institutionalized persons, $50 \%$ of fractures involve the hip, ${ }^{8}$ and $96 \%$ of hip fractures involve a fall. ${ }^{9}$ Data summarized in the American Geriatrics Society guidelines suggest that depression confers a higher mean relative risk for falls (2.2) than cognitive impairment (1.8) or age of 80 and older (1.7), which are far less modifiable. ${ }^{10}$

Depression is a highly disabling condition in itself, and when it is associated with significant medical illness, it can have a profound effect on capacity to recover. Depression also affects patients' daily function, their ability to sustain social networks and their quality of life and mortality from other causes. Poor physical function, such as during the prolonged recovery from a fracture, can predispose to depression. ${ }^{11}$ In turn, depressive symptoms and cognitive impairment have been associated with poorer participation in rehabilitation. ${ }^{5}$ Recovery from falls is often associated with risk for institutional placement, partly due to fear of further injury. Persons suffering hip fracture who had few depressive symptoms were three times as likely to achieve independence in walking and nine times as likely to return to their prior level of function. It appears that this is a specific effect of depression itself, not the effect of depression on related psychosocial factors. ${ }^{4}$ In another study, patients with high positive affect had better performance-based functioning after hip fracture. ${ }^{12}$ Thankfully, depression is a relatively modifiable condition no matter whether it is a cause or result of disability, but until now, there have been no studies identifying predictors of depression post hip fracture and none that address methods of prevention and intervention. As reported in this issue of $J A G S$, Dr. Lenze and his coworkers carefully examined clinical and demographic variables associated with the development of depression after hip fracture. ${ }^{13}$ They found that 18 of $126(14 \%)$ elderly hip fracture patients in a large urban hospital developed major depression (MDD). The majority $(61 \%)$ of these patients had the onset of MDD before discharge from the hospital, and no new cases of MDD were identified after 14 weeks until study termination at 26 weeks. Features of the injury itself, such as type or location of fracture, degree of disability at discharge, and type of surgery were not associated with the development of MDD; apathy was the only variable significantly associated with developing MDD in this study, giving us only limited clinical guidance for the treatment of patients at risk for developing depression after a hip fracture. In another publication Dr. Lenze reported an association between hip fracture, depression, and the 5-HTTLPR genotype. ${ }^{14}$ More research is needed to help identify patients at high risk for depression after hip fracture.

The treatment and prevention of depression in the context of hip fracture have also received little attention. Dr. Burns and his coworkers report here a pioneering study of structured nurse-led interventions to treat and prevent depression in patients with hip fractures. ${ }^{15}$ The study confirms high rates of depression in this population, but the results of the interventions tested are largely disappointing. Although more depressed patients improved in the intervention group (52\%) than in the controls $(34 \%)$, and fewer intervention patients $(6 \%)$ developed depression than control patients $(16 \%)$, these differences were not statistically significant. The two interventions also did not improve length of stay, functional outcomes, or pain. Given the relatively low incidence rates of depression observed, the authors may have had limited statistical power to identify a significant difference in their prevention study. Finally, the low participation rate in this trial $(49 \%)$ suggests how difficult it can be to implement interventions for such a frail and vulnerable population.

It has become well known that depression can complicate recovery from common medical illnesses in older people, but few reports so far have addressed preventive strategies or early interventions in this context. ${ }^{16-18}$ The reports in this month's JAGS break important new ground in this area but also suggest that more research is needed to give clinicians tools to help identify, prevent, and treat depression in such high-risk groups.

Barbara Kambolz, MD Department of Psychiatry University of Michigan VA Ann Arbor Health System Ann Arbor, MI

Jürgen Unützer, $M D$ Department of Psychiatry and Behavioral Sciences School of Medicine University of Washington Seattle, WA 


\section{ACKNOWLEDGMENTS}

Financial Disclosures: Dr. Kamholz has no connections with any industries and is not involved in research on this topic. Dr. Unützer has research grant support from the John A. Hartford Foundation, the American Federation of Aging Research, and the National Institute of Mental Health.

Author Contributions: Dr. Kamholz prepared the initial draft. Dr. Unützer provided additional comments. Sponsors' Role: None.

\section{REFERENCES}

1. Holmes JD, House AO. Psychiatric illness in hip fracture. Age Ageing 2000;29:537-546.

2. Fenton FR, Cole MG, Engelsmann F et al. Depression in older medical inpatients. Int J Geriatr Psychiatry 1994;9:279-284.

3. Nightingale S, Holmes J, Mason J et al. Psychiatric illness and mortality after hip fracture. Lancet 2001;357:1264-1265.

4. Mossey JM, Knott K, Craik R. The effects of persistent depressive symptoms on hip fracture recovery. J Gerontol 1990;45:M163-M168.

5. Lenze EJ, Munin MC, Dew MA et al. Adverse effects of depression and cognitive impairment on rehabilitation participation and recovery from hip fracture. Int J Geriatr Psychiatry 2004;19:472-478.

6. Jette AM, Harris B, Cleary PD et al. Functional recovery after hip fracture. Arch Phys Med Rehabil 1987;68:735-740.

7. Mussolino ME. Depression and hip fracture risk: The NHANES I epidemiologic follow-up study. Public Health Rep 2005;120:71-75.
8. Rubenstein LA, Josephson KR. The epidemiology of falls and syncope. Clin Geriatr Med 2002;18:141-158.

9. Norton R, Campbell AJ, Lee-Joe T et al. Circumstances of falls resulting in hip fractures among older people. J Am Geriatr Soc 1997;45:1108-1112.

10. American Geriatrics Society. Panel on Falls Prevention Guideline for the prevention of falls in older persons. J Am Geriatr Soc 2001;49:664-672.

11. Multran EJ, Reitzes DC, Mossey J et al. Social support, depression, and recovery of walking ability following hip fracture surgery. J Gerontol B Psychol Sci Soc Sci 1995;50B:S354-S361.

12. Fredman L, Hawkes WG, Black $S$ et al. Elderly patients with hip fracture with positive affect have better functional recovery over 2 years. J Am Geriatr Soc 2006;54:1074-1081.

13. Lenze EJ, Munin MC, Skidmore ER et al. Onset of depression in elderly persons after hip fracture: Implications for prevention and early intervention of late-life depression. J Am Geriatr Soc 2007;55:81-86

14. Lenze EJ, Munin MC, Ferrell RE et al. Association of the serotonin transporter gene-linked polymorphic region (5-HTTLPR) genotype with depression in elderly persons after hip fracture. Am J Geriatr Psychiatry 2005; 13:428-432.

15. Burns A, Banerjee S, Morris J et al. Treatment and prevention of depression after surgery for hip fracture in older people: Randomized, controlled trials. J Am Geriatr Soc 2007;55:75-80.

16. Anderson CS, Hackett $\mathrm{ML}$, House AO. Interventions for preventing depression after stroke. Cochrane Database Syst Rev 2004;(2):CD003689.

17. Lustman PJ, Clouse RE, Nix BD et al. Sertraline for prevention of depression recurrence in diabetes mellitus: A randomized, double-blind, placebocontrolled trial. Arch Gen Psychiatry 2006;63:521-529.

18. Whyte EM, Rovner B. Depression in late-life: Shifting the paradigm from treatment to prevention. Int J Geriatr Psychiatry 2006;21:746-751. 